\title{
SAND REPORT
}

SAND2002-2065

Unlimited Release

Printed July 2002

\section{Chem-Prep PZT 95/5 for Neutron Generator Applications: Particle Size Distribution Comparison Of Development and Production-Scale Powders}

Diana L. Sipola, James A. Voigt, Steven J. Lockwood, and Emily D. Rodman-Gonzales

Prepared by

Sandia National Laboratories

Albuquerque, New Mexico 87185 and Livermore, California 94550

Sandia is a multiprogram laboratory operated by Sandia Corporation, a Lockheed Martin Company, for the United States Department of Energy under Contract DE-AC04-94AL85000.

Approved for public release; further dissemination unlimited. 
Issued by Sandia National Laboratories, operated for the United States Department of Energy by Sandia Corporation.

NOTICE: This report was prepared as an account of work sponsored by an agency of the United States Government. Neither the United States Government, nor any agency thereof, nor any of their employees, nor any of their contractors, subcontractors, or their employees, make any warranty, express or implied, or assume any legal liability or responsibility for the accuracy, completeness, or usefulness of any information, apparatus, product, or process disclosed, or represent that its use would not infringe privately owned rights. Reference herein to any specific commercial product, process, or service by trade name, trademark, manufacturer, or otherwise, does not necessarily constitute or imply its endorsement, recommendation, or favoring by the United States Government, any agency thereof, or any of their contractors or subcontractors. The views and opinions expressed herein do not necessarily state or reflect those of the United States Government, any agency thereof, or any of their contractors.

Printed in the United States of America. This report has been reproduced directly from the best available copy.

Available to DOE and DOE contractors from

U.S. Department of Energy

Office of Scientific and Technical Information

P.O. Box 62

Oak Ridge, TN 37831

Telephone: (865)576-8401

Facsimile: (865)576-5728

E-Mail: reports@adonis.osti.gov

Online ordering: http://www.doe.gov/bridge

Available to the public from

U.S. Department of Commerce

National Technical Information Service

5285 Port Royal Rd

Springfield, VA 22161

Telephone: (800)553-6847

Facsimile: (703)605-6900

E-Mail: $\quad$ orders@ntis.fedworld.gov

Online order: http://www.ntis.gov/ordering.htm

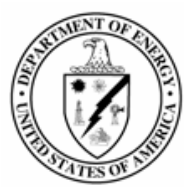


SAND2002-2065

Unlimited Release

Printed July 2002

\title{
Chem-Prep PZT 95/5 for Neutron Generator Applications: Particle Size Distribution Comparison of Development and Production-Scale Powders
}

\author{
Diana L. Sipola and James A. Voigt \\ Materials Chemistry Department \\ Steven J. Lockwood and Emily D. Rodman-Gonzales \\ Ceramic and Glass Department \\ Sandia National Laboratories \\ P.O. Box 5800 \\ Albuquerque, NM 87185-1411
}

\begin{abstract}
The Materials Chemistry Department 1846 has developed a lab-scale chem-prep process for the synthesis of PNZT 95/5, a ferroelectric material that is used in neutron generator power supplies. This process (Sandia Process, or SP) has been successfully transferred to and scaled by Department 14192 (Ceramics and Glass Department), (Transferred Sandia Process, or TSP), to meet the future supply needs of Sandia for its neutron generator production responsibilities. In going from the development-size SP batch $(1.6 \mathrm{~kg} / \mathrm{batch})$ to the production-scale TSP powder batch size $(10 \mathrm{~kg} / \mathrm{batch})$, it was important that it be determined if the scaling process caused any "performance-critical" changes in the PNZT $95 / 5$ being produced. One area where a difference was found was in the particle size distributions of the calcined PNZT powders. Documented in this SAND report are the results of an experimental study to determine the origin of the differences in the particle size distribution of the SP and TSP powders.
\end{abstract}




\section{Acknowledgments}

The authors would like to acknowledge Ted Montoya, Tom Spindle Jr., and Mike Hutchinson for the powder processing and sintering of the PZT materials used in this study. 


\section{Contents}

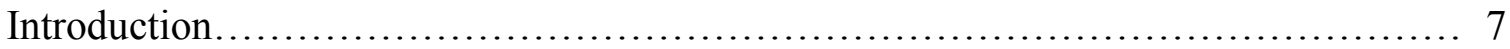

Purpose.................................................................. 7

Background .................................................................. 7

PNZT Powder Synthesis Overview ....................................... 7

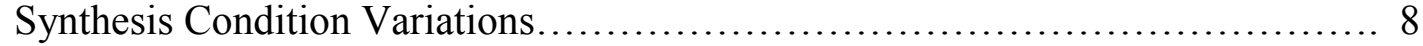

Post-Synthesis Processing Condition....................................... 8

SP Post-Synthesis Processing......................................... 8

TSP Post-Synthesis Processing ........................................ 9

Experimental............................................................. 10

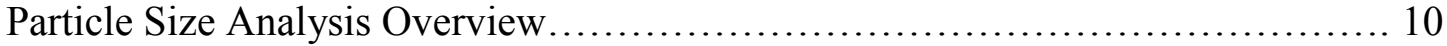

Experimental Procedure.................................................. 10

SP16T Powder Synthesis ................................................ 11

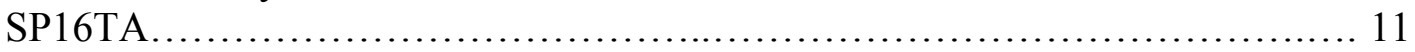

SP16TB............................................................. 11

TSP57 Powder Synthesis Series............................................. 12

TSP57A (3.4 kg final oxide powder)..................................... 12

TSP57B (5 kg final oxide powder....................................... 12

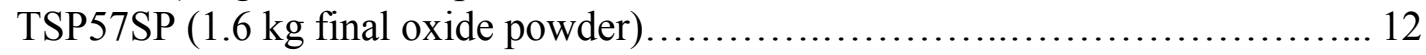

Results and Discussion........................................................ 13

SP16T Powder Series Particle Size Distributions.............................. 13

TSP57 Powder Series Particle Size Distributions............................. 13

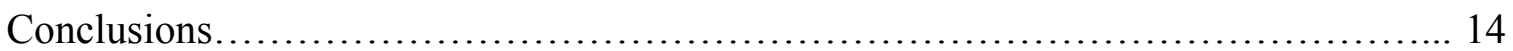

\section{Figures}

Figure 1. Overview of powder synthesis and powder processing of PNZT powder..... 16

Figure 2. Comparison of PSDs of SP Series and TSP "Center point" (CP) powders.... 16

Figure 3. Flow diagram illustrating the SP and TSP synthesis experiments........... 17

Figure 4. Comparison of PSDs for SP16TA and SP16TB ....................... 17

Figure 5. Comparison of the PSDs of the three sub-batches of TSP57 ................ 18

\section{Tables}

1 Post-synthesis processing and characterization data for SP16TA and SP16TB..... 13

2 Post-synthesis processing and characterization data for the three sub-batches of TSP57 
Intentionally Left Blank 


\title{
Chem-Prep PZT 95/5 for Neutron Generator Applications: Particle Size Distribution Comparison of Development and Production-Scale Powders
}

\author{
Introduction
}

\section{Purpose}

The Materials Chemistry Department 1846 has developed a lab-scale chem-prep process for the synthesis of PNZT 95/5, a ferroelectric material that is used in neutron generator power supplies (refer to SAND98-2750, Solution Synthesis and Processing of PZT Materials for Neutron Generator Applications, for an overview of the process). This process (Sandia Process, or SP) has been successfully transferred to and scaled by Department 14192 (Ceramics and Glass Processing Department), (Transferred Sandia Process, or TSP), to meet the future supply needs of Sandia for its neutron generator production responsibilities.

In going from the development-size SP batch $(1.6 \mathrm{~kg} / \mathrm{batch})$ to the production-scale TSP powder batch size $(10 \mathrm{~kg} / \mathrm{batch})$, it was important to determine if the scaling process caused any "performance-critical" changes in the PNZT 95/5 being produced. The particle size distribution (PSD), as well as compositional homogeneity of a powder, can play a role in the powder's densification, and subsequently in the electrical response and performance of the voltage bars fabricated from the sintered material when explosively functionally tested. Routine measurements have shown a PSD difference between SP and TSP powders. Documented in this SAND report are the results of two experimental studies to determine the origin of the PSD difference between the SP and TSP powders.

\section{Background}

\section{PNZT Powder Synthesis Overview}

The transfer of the SP process to Department 14192 for scale-up began during the summer of 1999. During the first two years of the process transfer, over 50 TSP batches were prepared, addressing numerous processing issues and parameters (details of which will be documented elsewhere). At the point of this study, a nominal set of processing conditions was identified. These were structured to match the SP development process as closely as possible as well as incorporating necessary modifications to meet the constraints of process scale-up. The SP16 series were prepared using synthesis equipment similar to that used for the synthesis of TSP powder (shear mixer, stirrers and pumps). An overview of the original SP process and the scaling effort to TSP can be seen in the flow chart (Figure 1). Outlined below are key synthesis parameters used in both processes: 
- preparation of the lead acetate solution one day prior to synthesis;

- filtering of the oxalic acid/n-propanol solution (5 $\mu \mathrm{m}$ Whatman Polycap 75 HD filter);

- n-butoxides of $\mathrm{Zr}$, Ti and $\mathrm{Nb} /$ glacial acetic acid mix time of 5 minutes (termed "alkoxides/glacial acetic acid solution) prior to addition to the $\mathrm{Pb}$ acetate solution;

- $\mathrm{Pb}$ acetate and alkoxides/glacial acetic acid solution mixed for 30 minutes (termed "metals solution") prior to the precipitation reaction;

- metals solution added to the oxalic acid/n-propanol solution at a pump setting of 55 rpm (Cole Parmer L/S Hazardous duty pump, Model P-07583-50; pump head Cole Parmer, Model 7529-10);

- beginning with TSP22 and SP16H, the shear mixer operated at $1750 \mathrm{rpm}$ (T50DX Ultra Turrax w/ 550N-G45F Dispersing Tool, IKA Works, Inc.) followed by an additional 5 minute shear mix period upon completion of the metals solution addition;

- stirred and aged the precipitant slurry for 90 minutes.

Synthesis condition variations: The principal difference between the SP and TSP synthesis routes was the volume of reagent chemicals used. As a result of scaling the powder synthesis process from the $1.6 \mathrm{~kg} / \mathrm{batch}$ SP size to the $10 \mathrm{~kg} / \mathrm{batch}$ TSP size, 6.25 times the amount of chemicals are used for the TSP batches relative to the SP. The alkoxides/glacial acetic acid solution, upon completion of the 5-minute mix time, was not filtered in the SP process, but, for the TSP process, the solution was filtered ( $5 \mu \mathrm{m}$ Whatman Polycap $75 \mathrm{HD}$ filter) prior to addition to the $\mathrm{Pb}$ acetate solution. Also, due to its clarity, the lead acetate solution used in SP batches was not filtered as was done for TSP batches ( $5 \mu \mathrm{m}$ Whatman Polycap 75 HD filter). Due to the flexibility allowed for the development-scale SP batches, the addition rate of the metals solution to the oxalic $\mathrm{acid} / \mathrm{n}$-propanol solution was varied (between $\sim 18$ and $\sim 55 \mathrm{rpm}$ for the peristaltic pump the same model pump and tubing size is used for both the SP and TSP processes). The addition rate for the TSP batches was not varied from its baseline set point of $55 \mathrm{rpm}$.

\section{Post-synthesis Processing Conditions}

The post-synthesis processing conditions vary for the SP and TSP batches. The main difference in the two processes is the method of filtration of the precipitant slurry prior to oven drying. A general outline for the processes is given below.

\section{$\underline{\text { SP Post-Synthesis Processing (1.6 kg final oxide powder): }}$}

- The $\sim 12$ L of precipitant slurry generated in an SP batch was vacuum filtered (KNF Neuberger, Inc. Laboport Model N840.3 FTP vacuum pump) in four 3 L sintered glass fritted filters ( 6.2 inch diameter each, "medium" frit) until a cracked filter cake was produced ( $\sim 1-2$ hours).

- The entire "wet" filter cake/filter assembly was covered with gauze and placed into a Blue M Friction-Aire (Model HS1202E) drying oven for 140 
hours at $\sim 88^{\circ} \mathrm{C}$. Upon drying, the cakes, which were chunky in character, were transferred to two large pails and broken up manually to a crumbly powder.

- The powder was pyrolyzed $\left(400^{\circ} \mathrm{C}\right.$ for 16 hours, split equally among 10 alumina crucibles, $14 \times 19 \times 4 \mathrm{~cm}$, no air flow, furnace described below) and ball milled for 7 hours (11.2 pounds of $3 / 8$ inch $\mathrm{ZrO}_{2}$ media in a 1 gallon wide mouth Nalgene bottle).

- For powders referred to in this SAND report, the media and powder were separated using a CSC Scientific Sieve Shaker utilizing a stacked array of sieves (No. 4 and No. 20 U.S.A. Standard Sieves, ASTM) at an intensity setting of 3.5 to 5 for 3 minutes per sieve loading. The powder plus media were placed onto a No. 4 (alternately, No. 10) sieve; the +20 mesh fraction $(>850 \mu \mathrm{m})$ was captured and isolated from the powder fraction collected for calcination.

- The powder was calcined at $900^{\circ} \mathrm{C}$ for 16 hours (split evenly among 3 covered alumina crucibles, $14 \times 19 \times 4 \mathrm{~cm}$ ). Two furnaces, a Fisher Isotemp muffle furnace (650 Series Model 126) and a Thermolyne muffle furnace (Model 6000), were used for high temperature powder processing. Both furnaces were used for the pyrolysis cycle. For calcination, only the Fisher Isotemp furnace was used.

\section{$\underline{\text { TSP Post-Synthesis Processing (10 kg final oxide powder): }}$}

- The precipitant slurry generated in a TSP batch $(\sim 85 \mathrm{~L})$ was vacuum filtered (house vacuum) in two 24-inch diameter polyethylene fritted filters lined with Whatman No. 3 ash less filter paper. Due to the large volumes of flammable solvents (n-propanol) in the slurry and equipment safety concerns, the precipitant slurry was allowed to filter/dry over the course of six days. During this filtering/drying period, the filter cakes were manually broken and mixed twice daily on days 1, 2, 5, and 6 after synthesis. Following the filtering/drying period, the cake (precursor powder) was further dried using a Hotpack drying oven (Model 217602-4) per the procedure below. This process was followed through batch TSP53, at which point, a Blue M Friction Aire oven (Model HS-3802-G) replaced the Hotpack drying oven (beginning with TSP54, July 2001). This new oven alleviated the equipment safety concerns, and permitted overnight vacuum filtration of the slurry prior to oven drying. This became the standard baseline condition beginning with TSP61 (with no manual break-up of the filter cake).

- After filtering, the precursor powder was loaded into 8-10 Pyrex trays (9 x 13 $\mathrm{x} 2$ inch), covered with gauze and dried at $88^{\circ} \mathrm{C}$ (overnight or up to $\sim 1.5$ days). The oven-dried powder was pyrolyzed (in the same glass trays as loaded for drying) at $400^{\circ} \mathrm{C}$ for 16 hours (air flow of $150 \mathrm{scfm}$ ) and then ball 
milled in two $15 \mathrm{~L}$ Nalgene carboys containing 38 pounds of $1 / 2$ inch $\mathrm{ZrO}_{2}$ media for 15 hours.

- For powders referred to in this SAND report, the media and powder were separated using a CSC Scientific Sieve Shaker utilizing a stacked array of sieves (U.S.A. Standard Sieve, ASTM) at an intensity setting of 3 for 3 minutes per sieve loading. The powder plus media were placed into two No. 4 sieves stacked upon a No. 20 sieve; the +20 mesh fraction was captured and isolated from the powder fraction collected for calcination.

- The powder was calcined at $900^{\circ} \mathrm{C}$ for 16 hours (split evenly among 6 crucibles of size $15 \times 20 \times 11 \mathrm{~cm}$, each covered with an inverted crucible, 18 x 23 x $12 \mathrm{~cm}$ ). A Lindberg Treet-All box furnace (Model 11-MT-183618$21 \mathrm{AM})$ was used for the high temperature powder processing.

\section{Experimental}

\section{Particle Size Analysis Overview}

The particle size distribution for powders described in this report were determined on calcined powders $\left(900^{\circ} \mathrm{C}\right.$ for 16 hours) using a Coulter Model LS230 particle size analyzer. Sample preparation involved using a $50 \mathrm{mg}$ aliquot of the powder, wetted with 2 drops of Darvan 821 A dispersant (R.T. Vanderbilt, $40 \%$ solution) to form a fluid paste, and then diluted with $20 \mathrm{~mL}$ of degassed, filtered $(0.2 \mu \mathrm{m})$ tap water. The slurry was stirred and ultrasonically dispersed simultaneously (Heat Systems Model W375 sonicator, with a $1 / 4$ inch micro tip, operated at $50 \%$ duty cycle and $50 \%$ power) for three minutes prior to analysis. An aliquot of this slurry was then introduced into the Coulter sample cell for the analysis. Three PSDs were obtained per aliquot, and the average distribution was calculated from these three PSD runs. To repeat an analysis, a fresh slurry sample was prepared as just described.

\section{Experimental Procedure}

The TSP powders have typically contained a small volume of particles greater than $\sim 10$ $\mu \mathrm{m}$. SP16 series powders show negligible material $>10 \mu \mathrm{m}$ (see Figure 2). The large particles seen in the TSP material (up to $80 \mu \mathrm{m}$ ) can lead to sintered-state defects such as porous regions, cusp pores, cracks, etc. These types of defects are suspected of reducing the performance characteristics of voltage bars. To identify the possible sources of the $>10 \mu \mathrm{m}$ fraction, two experiments were performed: one with SP batch processing, and one with TSP batch processing. Both experimental batches were split into sub-batches in an attempt to correlate the effects of the filtering and drying steps with the PSD differences between the development and production-scale processes. See Figure 3 for a flow diagram describing the SP and TSP synthesis experiments. 


\section{SP16T Powder Synthesis--Comparison of "SP-like" and "TSP-like" Filtering/Drying Conditions}

All of the SP development (1.6 kg) batches were synthesized in Building 897, however, batch SP16T was synthesized using the nominal SP conditions, but synthesized in Building 878 using the TSP production equipment (excluding the glassware for the metals solution). The slurry was divided post-synthesis to evaluate the effect of "SP-like" and "TSP-like" filtering/drying processes on the particle size of the powder. The SP process is a single batch process in which the precipitation reaction (reaction of the metals with the oxalic acid/n-propanol precipitant solution) occurs in 6-17 minutes, depending on the selected metals solution flow rate (SP16T reacted in 12 minutes).

SP16TA: This portion of the batch was processed to model an SP batch.

Approximately $25 \%$ of the $\sim 12$ L slurry was vacuum filtered (house vacuum in Building 878) in one $3 \mathrm{~L}$ sintered glass fritted ("SP") filter until a filter cake was formed (2.3 hours). The "wet" filter cake/filter assembly was oven dried (Blue M oven located in $897 / 2081$ ) for 140 hours at $\sim 88^{\circ} \mathrm{C}$. Upon drying, the manual breakup of the oven-dried powder was done in one plastic pail. The powder was pyrolyzed at $399^{\circ} \mathrm{C}$ or $412^{\circ} \mathrm{C}$ (two furnaces were used) in 3 crucibles, followed by ball milling for 7 hours (424 g pyrolyzed powder with $1428 \mathrm{~g}$ of $3 / 8$ inch $\mathrm{ZrO}_{2}$ media in a $1 \mathrm{~L}$ wide mouth Nalgene bottle). The media and powder were separated as described per the SP Post-Synthesis Processing above (No. 10 and No. 20 U.S.A. Standard Sieves, ASTM) at an intensity setting of 3.5 to 4 for 3 minutes per sieve loading. A +20 mesh fraction of $1.24 \mathrm{~g}$ was collected. The powder was calcined at $903^{\circ} \mathrm{C}$ for 16 hours in 1 covered crucible.

SP16TB: The remaining slurry from SP16T was filtered to emulate TSP postsynthesis processing conditions. The filtering and oven drying steps were done in Building 878. The slurry was vacuum filtered in an 18-inch diameter polyethylene fritted filter (lined with Whatman No. 3 ash less filter paper) for 24 hours. The very dry oxalate precursor powder cake $(\sim 1.5$ inch thick) was broken up in the filter and loaded into two Pyrex trays and dried in the Hotpack drying oven for $\sim 24$ hours at $88^{\circ} \mathrm{C}$. The dried powder sat uncovered in the drying oven over the weekend at room temperature prior to pyrolysis. The powder was pyrolyzed at $399^{\circ} \mathrm{C}$ or $412^{\circ} \mathrm{C}$ (two furnaces were used) in 7 crucibles, and ball milled for 7 hours ( $764 \mathrm{~g}$ pyrolyzed powder with $2571 \mathrm{~g}$ of $3 / 8$ inch $\mathrm{ZrO}_{2}$ media in a 0.5 gallon wide mouth Nalgene bottle). The media and powder were separated as described earlier (No. 4 and No. 20 U.S.A. Standard Sieves, ASTM) at an intensity setting of 3.5 to 5 for 3 minutes per sieve loading. A +20 mesh fraction of $<0.1 \mathrm{~g}$ was collected. The powder was calcined at $903^{\circ} \mathrm{C}$ for 16 hours in 2 covered crucibles.

To eliminate processing variables between these two sub-batches, they were pyrolyzed and calcined side by side during the same furnace runs (furnaces located in Building 897). 


\section{TSP57 Powder Synthesis Series-Comparison of Three Different Filtering/Drying Conditions}

A ten $\mathrm{kg}$ TSP batch was prepared using nominal TSP synthesis conditions and was divided post-synthesis into three sub-batches to evaluate if varying filtering/drying processes affects powder particle size distributions (see Figure 3 flow diagram). The 10 $\mathrm{kg} / \mathrm{batch}$ TSP chem-prep synthesis process consists of precipitating four $(2.5 \mathrm{~kg})$ sublots prepared sequentially (reaction of the metals solution with the oxalic acid/n-propanol precipitant solution) over the course of $\sim 2$ hours. The descriptions of the sub-batches for filtering/drying conditions are outlined below. Sub-batches TSP57A and TSP57B were processed through calcination in Building 878 per normal TSP processing. Powders TSP57A and 57B were pyrolyzed in separate furnace runs, but calcined in the same furnace run. TSP57SP was processed post-filtering in Building 897 per normal SP processing.

TSP57A (3.4 kg): The precipitant slurry remaining from synthesis sublot 3 (after the TSP57SP aliquot was removed--see below), combined with the slurry from synthesis sublot 4, was vacuum filtered (filter \#2) overnight prior to being dried in the Blue $\mathrm{M}$ drying oven for 31 hours in four Pyrex trays. The oven-dried powder was pyrolyzed (separately from TSP57B) followed by ball milling for 15 hours (3272 g pyrolyzed powder with $38.2 \mathrm{lbs}$. of $1 / 2$ inch $\mathrm{ZrO}_{2}$ media) in a $15 \mathrm{~L}$ Nalgene carboy. Separation of the media from the powder was accomplished as per the TSP Post-Synthesis Processing section as described above. A +20 mesh fraction of $5.19 \mathrm{~g}$ was collected. After a fourday delay, the powder was calcined in 3 crucibles.

TSP57B $(5.0 \mathrm{~kg})$ : The precipitant slurry from synthesis sublots 1 and 2 was vacuum filtered (filter \#1) for six days (with manual powder break-up of the filter cake twice daily on days 1, 2, 5 and 6 after synthesis) prior to being dried in the Blue $\mathrm{M}$ drying oven for 28 hours in four Pyrex trays. After pyrolysis, the powder was ball milled for 15 hours (4559 g pyrolyzed powder with $38.6 \mathrm{lbs}$. of $1 / 2$ inch $\mathrm{ZrO}_{2}$ media) in a $15 \mathrm{~L}$ Nalgene carboy. Separation of the media from the powder and calcination of the powder was done as described for TSP57A. The +20 mesh fraction collected for this sub-batch was $55.5 \mathrm{~g}$.

TSP57SP (1.6 kg): A volume of precipitant slurry ( 12 L) from synthesis sublot 3 was filtered in four $3 \mathrm{~L}$ sintered glass fritted (SP) filters in Building 878 using house vacuum ( $\sim 1.5$ to 2 hours until a filter cake formed). The filters were transferred to Building 897 for post-synthesis processing using SP conditions and equipment as described in the SP Post-Synthesis Processing section above. After oven drying for 140 hours, and manual break-up, the powder was pyrolyzed at $397^{\circ} \mathrm{C}$ or $408^{\circ} \mathrm{C}$ (two furnaces were used) in 10 crucibles, followed by ball milling for 7 hours ( $1530 \mathrm{~g}$ pyrolyzed powder with $11.2 \mathrm{lbs}$. of $3 / 8$ inch $\mathrm{ZrO}_{2}$ media) in a 1-gallon wide mouth Nalgene bottle. The media and powder were separated as previously described (No. 4 and No. 20 U.S.A. Standard Sieves, ASTM) at a setting of 3.5 to 4 for 3 minutes per sieve loading. A +20 mesh fraction of $1 \mathrm{~g}$ was collected. The powder was calcined at $900^{\circ} \mathrm{C}$ for 16 hours in 3 covered crucibles. 


\section{Results and Discussion}

\section{SP16T Powder Series Particle Size Distributions}

The PSD for the two sub-batches from this SP batch are shown in Figure 4 and summarized in Table 1. As has been typical for the SP16 powders, there is no tail for SP16TA (the SP-like processed sub-batch). However, SP16TB, the TSP-like processed sub-batch, contains 8-10 volume \% of particles greater than $9.82 \mu \mathrm{m}$. Since this $1.6 \mathrm{~kg} \mathrm{SP}$ batch was synthesized using TSP equipment (excluding the glassware for the metals solution), these results point to the difference in filtering/drying as being the source of the large particle size fraction in the SP16TB sub-batch. (The weekend delay between drying and pyrolyzing the material is not expected to affect PSD.) It should be noted that the $\sim 75 \%$ volume of precipitant slurry of SP16TB ( $\sim 9 \mathrm{~L})$, when filtered in the 18 inch diameter polyethylene fritted filter, resulted in a very dry cake of $\sim 1.5$ inch thick after 24 hours of vacuum filtration. In comparison, the filter cake thickness of a $10 \mathrm{~kg}$ TSP batch (2@ 24 inch diameter funnels) is $\sim 4.5$ inch after filtration.

A second interesting observation is the difference in the sintered density, as shown in Table 1. The SP-like sub-batch (SP16TA, HF905) has a density $\sim 0.09 \mathrm{~g} / \mathrm{cc}$ higher than that of either of the two high fires processed from the TSP-like sub-batch (SP16TB). This is consistent with earlier observations, where the SP powders tend to have higher sintered densities than the TSP powders. Also, these slugs had higher than normal open porosities of 2.1\% (SP16TA) and $3 \%$ (SP16TB). Due to the limited quantities of either SP16TA or SP16TB powders, a manual method was used to mix the binder solution and pore former into the PNZT powder, rather than the typical, twin-shell, blending process. The higher open porosity may be due to the difficulties of mixing small amounts of binder (2\% HA4) and pore former (1.8\% Avicel) into the PNZT powder.

Table 1. Post-synthesis Processing and Characterization Data for SP16TA and SP16TB

\begin{tabular}{|c|c|c|c|c|c|c|}
\hline Batch ID & $\begin{array}{c}\text { Wt.\% } \\
\text { recovery } \\
\text { after } \\
\text { pyrolysis }\end{array}$ & $\begin{array}{c}\text { Wt.\% } \\
\text { recovery } \\
\text { after } \\
\text { calcination }\end{array}$ & $\begin{array}{c}\mathbf{+ 2 0} \text { mesh } \\
\text { fraction, g }\end{array}$ & $\begin{array}{c}\text { Final } \\
\text { calcined } \\
\text { Powder, g }\end{array}$ & $\begin{array}{c}\text { Ave. Mean } \\
\text { Particle Size, } \\
\text { microns } \\
\text { (ave. vol.\% }> \\
\mathbf{9 . 8 2} \text { microns) } \\
\text { (2 sets of 3 runs } \\
\text { for SP16TB) }\end{array}$ & $\begin{array}{c}\text { HF Bulk Density, } \\
\text { g/cc } \\
\mathbf{1 . 8} \text { wt.\% Avicel } \\
\text { (\% Open Porosity) } \\
\text { (HF \#) }\end{array}$ \\
\hline $\begin{array}{c}\text { SP16TA } \\
\text { (SP-like) }\end{array}$ & 60.8 & 96.8 & 1.24 & 404.5 & $3.32(0.08 \%)$ & $7.459(2.1 \%)(\mathrm{HF} 905)$ \\
\hline $\begin{array}{c}\text { SP16TB } \\
\text { (TSP-like) }\end{array}$ & 55.7 & 97.4 & $<0.1$ & $\sim 735.6$ & $\begin{array}{c}6.35(10.7 \%), \\
6.05(8.6 \%)\end{array}$ & $7.368(3.0 \%)(\mathrm{HF} 903 \mathrm{~A})$ \\
$7.372(2.9 \%)(\mathrm{HF} 903 \mathrm{~B})$
\end{tabular}

\section{TSP57 Powder Series Particle Size Distributions}

The PSD for the three sub-batches of TSP57 are shown in Figure 5. A significant particle size distribution fraction $>10 \mu \mathrm{m}$ is seen for all three sub-batches regardless of the filtering/drying conditions used for the sub-batches. It is apparent, for the synthesis of TSP57, that the method of filtration/oven drying of the oxalate precursor powder does not affect the PSD of the final calcined powder, assuming that ball mill conditions had no 
effect. Also, as shown in Figure 5, there does not appear to be a difference in the PSD using the one-day (TSP57A) vs. the six-day (TSP57B) vacuum filtration cycle in conjunction with the use of the Blue $\mathrm{M}$ drying oven for the $88^{\circ} \mathrm{C}$ drying.

Table 2 shows the post-synthesis processing and characterization data for the three subbatches of TSP57. Again, consistent with the SP16T and previous SP and TSP run data, the SP-like sample (TSP57SP) had the highest sintered density. Also, it had the lowest +20 mesh fraction, indicating that it behaved differently with respect to the ball milling process or the ball milling processes themselves are different.

Table 2. Post-synthesis Processing and Characterization Data for the Three Sub-batches of TSP57.

\begin{tabular}{|c|c|c|c|c|c|c|}
\hline Batch ID & $\begin{array}{l}\text { Wt. } \% \\
\text { recovery } \\
\text { after } \\
\text { pyrolysis }\end{array}$ & $\begin{array}{c}\text { Wt.\% } \\
\text { recovery } \\
\text { after } \\
\text { calcination }\end{array}$ & $\begin{array}{l}+20 \text { mesh } \\
\text { fraction, } g\end{array}$ & $\begin{array}{c}\text { Final } \\
\text { calcined } \\
\text { Powder, g }\end{array}$ & $\begin{array}{c}\text { Ave. Mean } \\
\text { Particle Size, } \\
\text { microns } \\
\text { (ave. vol.\% }> \\
9.82 \text { microns) } \\
\text { (2 sets of } 3 \text { runs } \\
\text { for A \& B) }\end{array}$ & $\begin{array}{c}\text { HF } \\
\text { BulkDensity, } \\
\text { g/cc } \\
\text { 0.9 wt\% Lucite } \\
\text { (\% Open Porosity) } \\
\text { (HF) }\end{array}$ \\
\hline $\begin{array}{c}\text { TSP57A } \\
\text { (1 day vac) }\end{array}$ & 59.9 & Unavailable & 5.19 & 3480 & $\begin{array}{l}4.63(6.6 \%) \\
4.07(5.1 \%)\end{array}$ & $\begin{array}{c}7.346(0.071 \%) \\
\text { (HF945) }\end{array}$ \\
\hline $\begin{array}{c}\text { TSP57B } \\
\text { (6 day vac) }\end{array}$ & 59.5 & Unavailable & 55.5 & 4721 & $\begin{array}{l}4.47(5.7 \%) \\
3.83(5.0 \%)\end{array}$ & $\begin{array}{c}7.366(0.072 \%) \\
\text { (HF947) }\end{array}$ \\
\hline $\begin{array}{c}\text { TSP57-SP } \\
\text { (SP-like) } \\
\text { (2 hr vac) }\end{array}$ & 60.3 & 97.5 & 1.0 & 1476 & $3.92(4.3 \%)$ & $\begin{array}{c}7.387(0.061 \%) \\
\text { (HF943) }\end{array}$ \\
\hline
\end{tabular}

\section{Conclusions}

Comparing the PSD results for these two series of powder synthesis experiments reveals interesting observations, which are somewhat inconclusive. First, when a SP-synthesized powder is filtered and dried under TSP-like conditions, the large particle size fraction tail is present (SP16TB). This indicates that the TSP filtering and drying conditions negatively influence the final agglomeration state of the resulting calcined powder. The large agglomerates $(>10 \mu \mathrm{m})$ can adversely affect powder consolidation and subsequent densification during sintering. The question is whether or not the tail is dependent solely on the TSP filtering and drying steps. The results from the TSP57 batch study show that apparently this is not the case. For TSP57, all three sublots had a significant volume fraction of material greater than $10 \mu \mathrm{m}$ - even for the SP-like filtered and dried sample (TSP57SP). This indicates that at least some of the agglomerates that make up the $>10$ $\mu \mathrm{m}$ size particle size fraction in the final powder are formed during the TSP precipitation step.

The filtration step may also contribute to the formation of the larger agglomerates. Consider the fact that the largest fraction of particles $>10 \mu \mathrm{m}$ was for powder SP16TB the sublot of the SP batch that was filtered and dried like a TSP batch. As previously discussed, although this sample was treated "TSP-like," there were significant differences in how it was filtered from a standard TSP batch. This was because the quantity of 
precipitate for this sub-lot sample was significantly smaller than a standard TSP filter sublot. Because of the reduced amount of precipitate, it had a much thinner filter cake (thickness of 1.5 in. versus 4.5 in. for a standard TSP). As a result of the filter cake being thinner, the fraction of precipitate that was in contact with the filter was much higher than for a standard TSP cake. If large size agglomerates are formed in that portion of the cake that is in contact with or close to the filter, then the SP16TB should have the largest PSD tail - as was the case. A possible reason increased agglomeration may occur in the region at or around the cake/filter interface, is that this portion of the cake experiences the largest compaction pressure during vacuum filtration. The increased pressure may produce denser, stronger agglomerates that do not breakdown during subsequent processing.

Although not definitive, the results of this work have shed light onto where the larger agglomerates in the TSP PNZT 95/5 powders are formed. It appears that they form both during precipitation and filtration/drying (the effects of ball milling have not been investigated). Their importance with respect to impacting PNZT performance will be the subject of a future SAND report. 

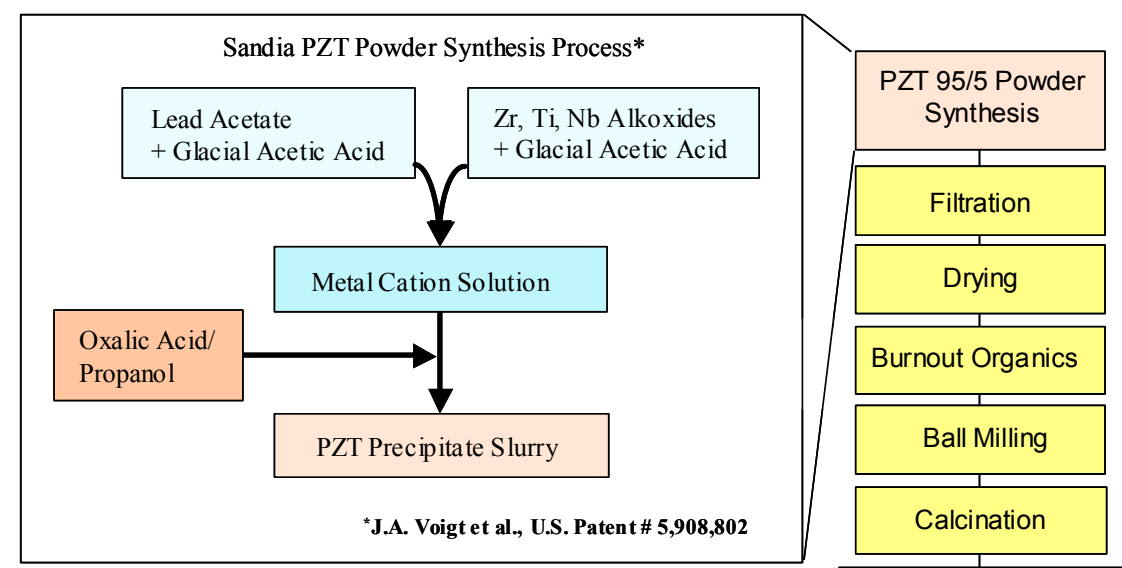

Scaling of SP to TSP:

From $1.6 \mathrm{~kg}$ to $10 \mathrm{~kg}$
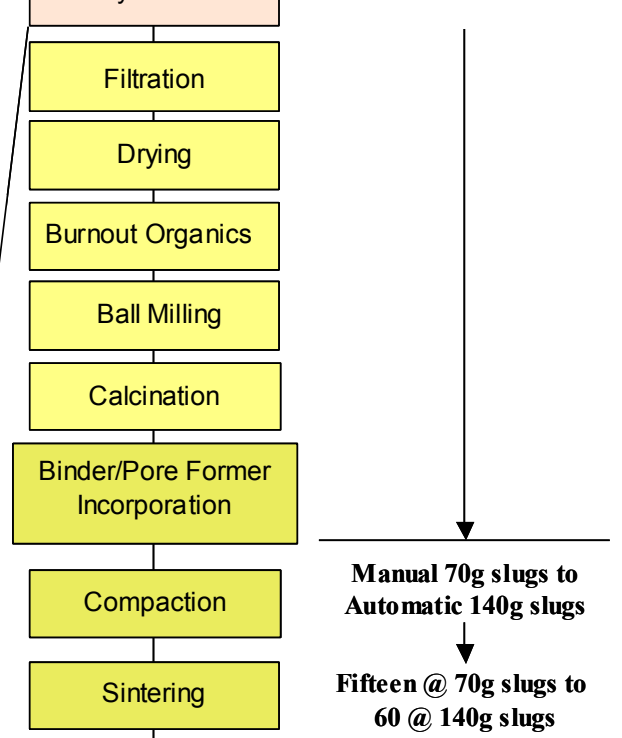

PZT Ceramic Slug

Figure 1. Overview of powder synthesis and powder processing of PNZT powder.

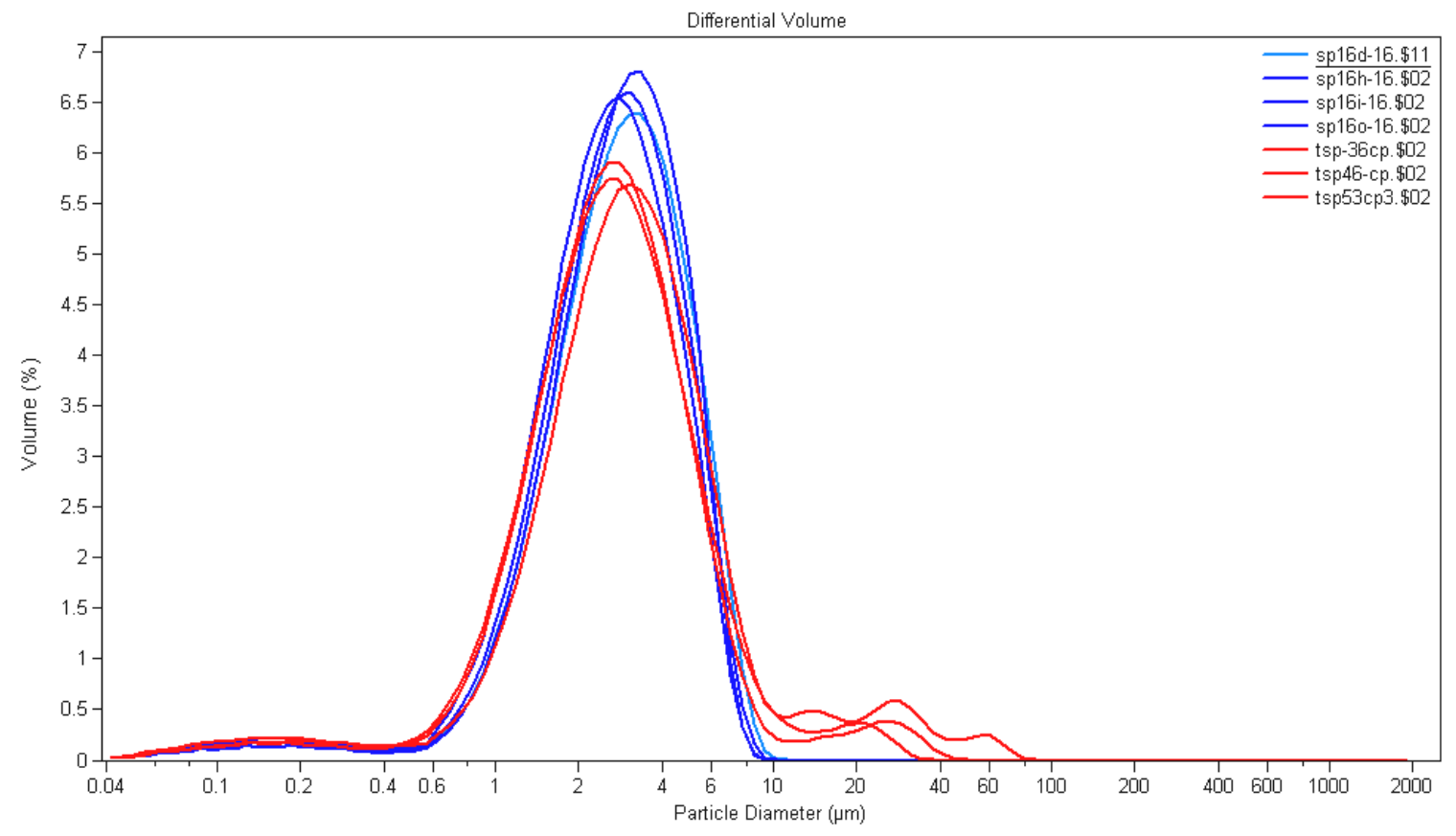

Figure 2. Comparison of PSDs of SP16 Series and TSP "Center point" (CP) powders. 

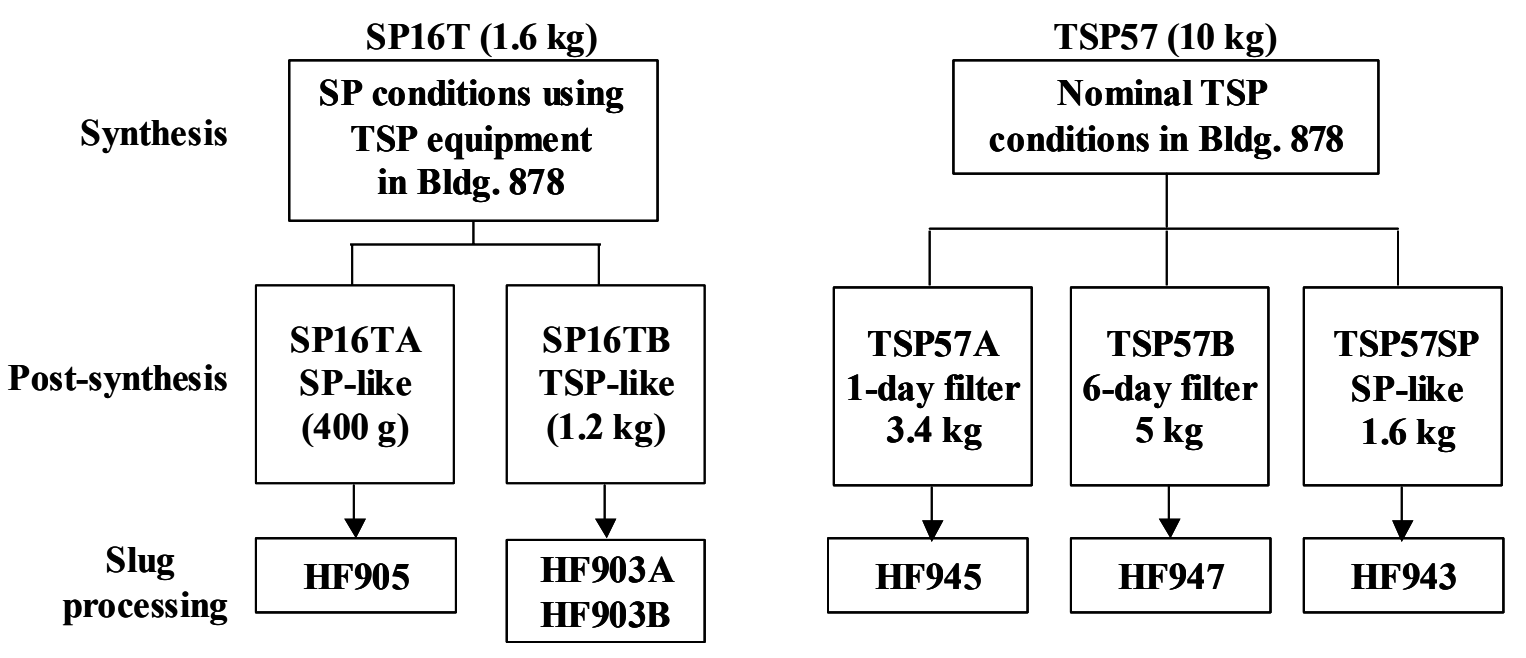

Figure 3. Flow diagram illustrating the SP and TSP synthesis experiments.

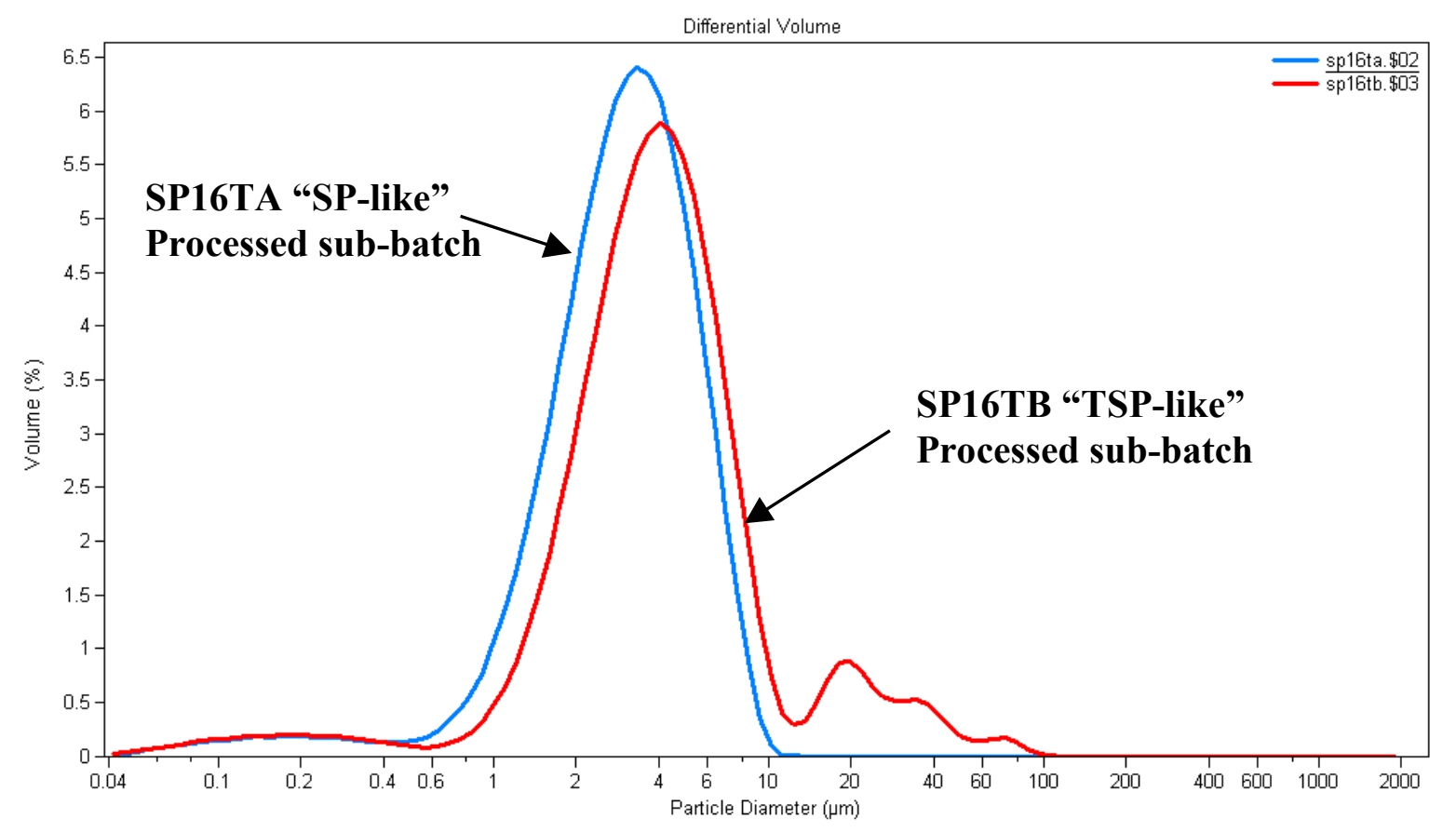

Figure 4. Comparison of PSD for SP16TA and SP16TB. 


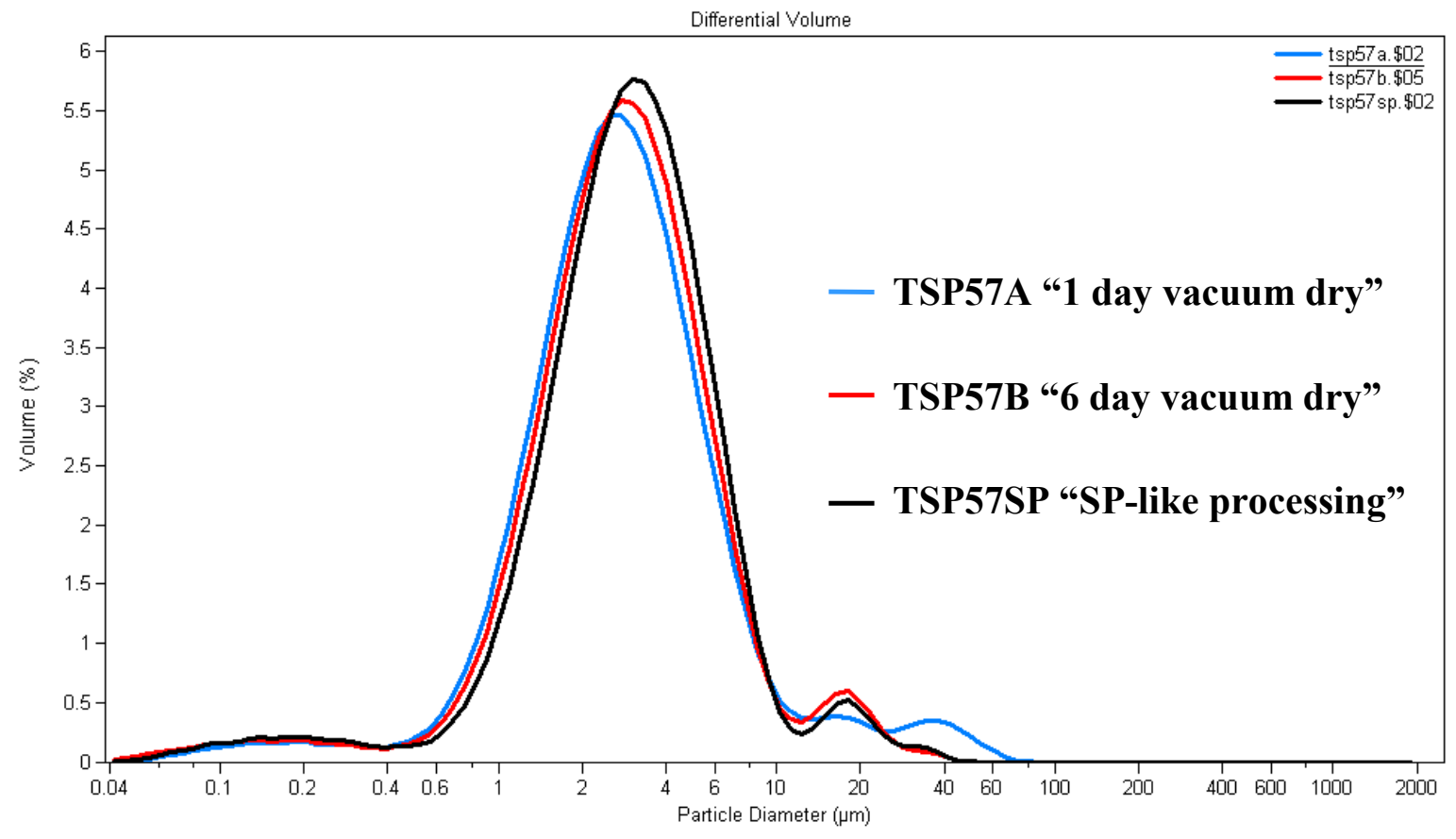

Figure 5. Comparison of the PSD of the three sub-batches of TSP57. 
Distribution:

$\begin{array}{rrl}1 & \text { MS0889 } & \text { S. J. Glass, 1843 } \\ 1 & 0889 & \text { C. S. Watson, 1843 } \\ 1 & \text { MS1349 } & \text { K. G. Ewsuk, 1843 } \\ 1 & 1349 & \text { W. F. Hammetter, 1843 } \\ 1 & \text { MS1411 } & \text { B. G. Potter, 1846 } \\ 3 & 1411 & \text { D. L. Sipola, 1846 } \\ 5 & 1411 & \text { J. A. Voigt, 1846 } \\ 1 & \text { MS0515 } & \text { J. D. Keck, 2561 } \\ & & \\ 1 & \text { MS0521 } & \text { T. W. Scofield, 2561 } \\ 1 & \text { MS0959 } & \text { T. J. Gardner, 14192 } \\ 1 & 0959 & \text { J. T. Gibson, 14192 } \\ 1 & 0959 & \text { J. P. Hanlon, 14192 } \\ 1 & 0959 & \text { M. A. Hutchinson, 14192 } \\ 3 & 0959 & \text { S. J. Lockwood, 14192 } \\ 1 & 0959 & \text { R. H. Moore, 14192 } \\ 1 & 0959 & \text { E. D. Rodman-Gonzales, 14192 } \\ 1 & 0959 & \text { P. Yang, 14192 } \\ 1 & & \text { Central Technical Files, 8940-2 } \\ 1 & \text { MS9018 } & \text { Technical Library, 9616 } \\ 1 & 0899 & \text { Review \& Approval Desk, 9612 } \\ 1 & & \text { For DOE/OSTI } \\ & & \text { LDRD Office, 1030 } \\ & & \end{array}$

